
76 巻 768 号 $(2010-8)$

\title{
小型空冷ファンの風量に及ぼす障害物の影響*
}

$$
\begin{array}{llll}
\text { 中村 } & \text { 元 }^{* 1} \text {, 福 江 高 志*2 } \\
\text { 小泉 雄 } \text { 大 }^{* 3} \text {, 石 塚 } & \text { 勝*4 }
\end{array}
$$

\section{Reduction in Flow Rate of Small Cooling Fans by an Obstruction}

\author{
Hajime NAKAMURA*5 ${ }^{* 5}$ Takashi FUKUE, \\ Katsuhiro KOIZUMI and Masaru ISHIZUKA \\ *5. Department of Mechanical Engineering, National Defense Academy, \\ 1-10-20 Hashirimizu, Yokosuka-shi, Kanagawa, 239-8686 Japan
}

\begin{abstract}
A compact air-cooling device often encounters high-density mounting environment, which may reduce a flow-rate of a cooling fan. In this work, the PQ characteristics of a cooling fan was investigated which varied by placing an obstacle in close proximity of a fan. Small axial-flow fans of 30-80 mm in side length and small centrifugal fans of $35-52 \mathrm{~mm}$ in side length were tested here. As a result, it was found that the maximum flow rate for the free air-flow begin to decrease when the opening area of the gap-flow between the fan and the obstacle becomes smaller than twice the fan flow area, and decreases suddenly if it becomes smaller than the fan flow area. This relation was almost independent of type and size of a fan, rotation speed of impeller, and shape and position of an obstacle.
\end{abstract}

Key Words: Electronic Equipment, Flow Measurements, Turbomachinery, Cooling Fan, PQ Characteristic

\section{1.まえがき}

最近，電子機器の小型化・薄型化に伴って筐体が 高密度に実装されるようになり，強制空冷機器では， 空冷ファンのごく近傍にも部品などの障害物が設置さ れるケースが多くなっている。しかし，障害物によっ て通風が妨げられると，ファンの風量-圧力特性（PQ 特性）が力タログ值から外れ，予期せぬ風量低下を招 く恐れがある。実際，ファンの近傍に邪魔板などの障 害物が存在すると，ファンの $\mathrm{PQ}$ 特性が変化すること が報告されている(1-4).

そこで本研究では, 小型の電子機器で使用される 小型の然泠ファン（軸流ファン及び遠心ファン）を用 い，その近傍に障害物を設置したときの $\mathrm{PQ}$ 特性の変 化を実験的に調べた。また，障害物の形状や設置位直 を変化させ、ファンの風量を低下させる主な要因につ いて検討すると共に，風量の低下が顕著になる一般的

*原稿受付 2010 年 1 月 14 日.

*1 正員，防衛大学校機械工学科(焉 239-8686 横須賀市走水 110-20)

*2 正員, 富山県立大学大学院工学研究科(西 939-0398 射水市 黑河 5180).

*3 正員,コ一セル (株) 開発部 (丞930-0816 富山有上赤江町 1 6-43)

*4 正員, フェロー, 富山目让大学工学部.

E-mail : nhajime@nda.ac.jp
な条件の提示を試みた。

\section{記 号}

$$
\begin{aligned}
A_{f} & : \text { ファン内部（吐出口）の通風面積 } \\
A_{g} & : \text { ファンと障害物の隙間最小面積 } \\
b & : \text { 障害物によるファン開ロ部の閉塞長さ } \\
d_{L}, & : \text { ファンのフレム辺長 } \\
d_{f}, d_{h} & : \text { ファンのフレーム開口部直径, 八ブ直径 } \\
d_{o} & : \text { 障害物の直径あるいは辺長 } \\
g & : \text { ファンと障害物の隙間 } \\
P & : \text { 圧カ }[\mathrm{Pa}] \\
\Delta P_{c h} & : \text { チャンバー法によるファン前後静圧差 }[\mathrm{Pa}] \\
Q, Q_{0} & : \text { 風量, 障害物が無い場合の開放風量 }\left[\mathrm{m}^{3} / \mathrm{s}\right] \\
u & : \text { 風速 }[\mathrm{m} / \mathrm{s}] \\
W & : \text { ファンが流体になす仕事率 }[\mathrm{W}] \\
\beta & : \text { 開ロ比 } \\
\beta_{g} & : \text { ファンと障害物の隙閒開口比 }=A_{g} / A_{f} \\
\rho & : \text { 空気の密度 }\left[\mathrm{kg} / \mathrm{m}^{3}\right] \\
\text { 字 } & \\
i, e, g & : \text { ファン吸込ロ, 吐出ロ, 障害物との隙間 }
\end{aligned}
$$

\section{2. 実験装置および方法}

図 1 に実験装置を示す。実験には，チャンバー，才 
リフィス流量計，風量・圧力差調整用バルブおよび補 睛ファンから成るファン性能測定装置 ${ }^{(5)}$ を用いた，供 試ファンをチャンバー端に設置した状態で，供試ファ ン前後の静圧差（チャンバーと大気の差圧） $\Delta P_{c h}$ お よび装置内の風量 $Q$ を測定することで, ファンの $\mathrm{PQ}$ 特性を得ることができる，流れを整流するため，チャ ンバー内には網 2 枚およびパンチングプレート（開口 比 0.3）が設置されている。また，オリフィス流量計 の上流端には明石式整流板 ${ }^{(6)}$ が設置されている。 アン前後の静圧差およびオリフィス板前後の差圧の測 定には微差圧計（DPI262, Druck）またはベッッ型マ ノメータ(ツクバリカセイキ)を用いた。

なお，本実験で用いた供試ファンは風量が小さく， 絞り流量計の JIS 規格 ${ }^{(6)}$ で定められている風量の下限 $\left(R e_{D}=5000, D\right.$ はオリフィス板上流側の管路の直

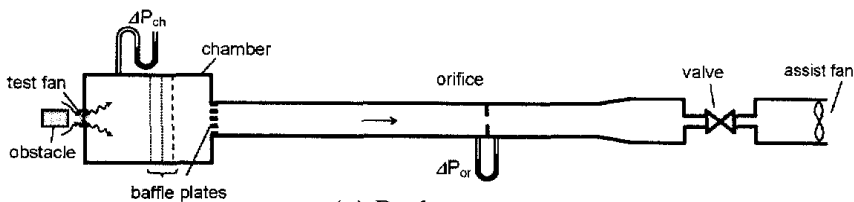

(a) Push setup

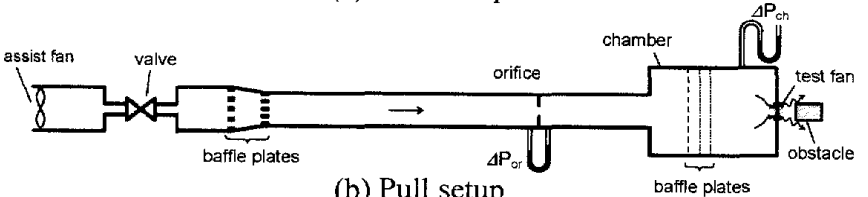

Fig. 1 Experimental setup

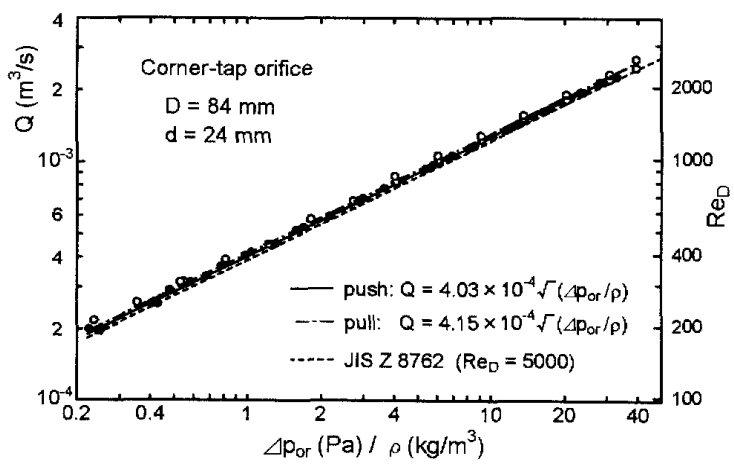

Fig. 2 Calibration result of the orifice meter

Table 1 Test fans

\begin{tabular}{|c|c|c|c|c|}
\hline type & maker (description) & size (mm) & rating & $\begin{array}{c}\text { rpm } \\
\left(\Delta P_{c h}=0\right)\end{array}$ \\
\hline axial-1 & Copal (F310R-05LC) & $\square 30 \times 10$ & $5 \mathrm{~V}$ & 7200 \\
\hline axial-2 & Sanyo (109P0412H902) & $\square 40 \times 10$ & $12 \mathrm{~V}$ & 6500 \\
\cline { 4 - 5 } & & $10 \mathrm{~V}$ & 5300 \\
\hline axial-3 & Sanyo (9A0812H4D031) & $\square 80 \times 25$ & $12 \mathrm{~V}$ & 2900 \\
\hline centrif-1 & Sunon (GB0535AEB1-8) & $\square 35 \times 6$ & $5 \mathrm{~V}$ & 8500 \\
\hline centrif-2 & Sanyo (109BC12GA7) & $\square 52 \times 15$ & $12 \mathrm{~V}$ & 6400 \\
\cline { 4 - 5 } & & & $10 \mathrm{~V}$ & 5950 \\
\hline
\end{tabular}

径）を下回るため,オリフィス流量計は事前に容積流 量計（ガスオーバル GAL55, オーバル社: 流量範囲 1.8 $\times 10^{-4} \sim 2.8 \times 10^{-3} \mathrm{~m}^{3} / \mathrm{s}$ ，精度 $\pm 1 \% \mathrm{FS}$ 以下）を用いて 校正した。校正結果を図 2 に示寸。JIS 規格の下限を

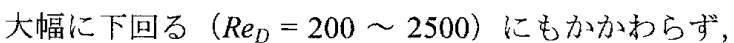
JIS 規格の計算式から求めた風量との差は $5 \%$ 程度と 小さく,データのばらつきも $5 \%$ 以内であった。

表 1 に供試ファンの一覧を示す。本実験では，小 型の軸流ファン（フレーム辺長 $30,40,80 \mathrm{~mm}$ ) およ び小型の遠心ファン（フレーム辺長 $35,52 \mathrm{~mm}$ ）を用

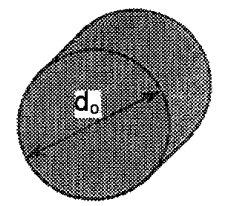

(a) Circular cylinder

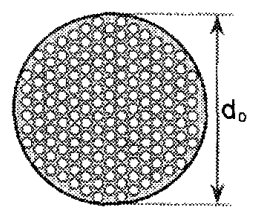

(c) Perforated plate 1 $(\beta \approx 0.5, \phi 4.5 \times 163)$

\section{$\mathrm{d}_{\mathrm{o}}$}

(b) Square plate

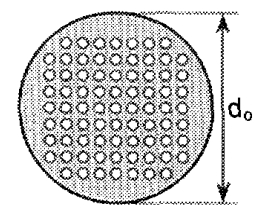

(d) Perforated plate 2 $(\beta \approx 0.3, \phi 4.5 \times 77)$
Fig. 3 Shape of obstacles

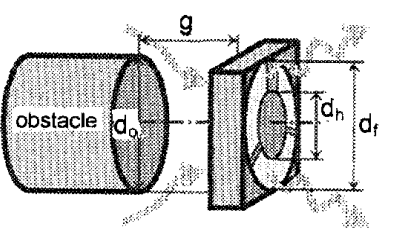

Front side

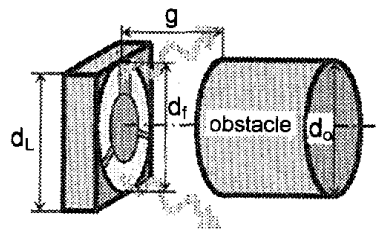

Rear side (a) Axial-flow fan obstructed by a circular cylinder

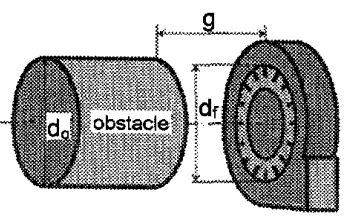

Front side

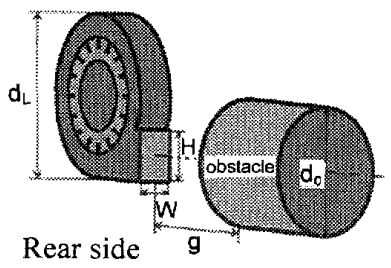

Rear side (b) Centrifugal fan obstructed by a circular cylinder
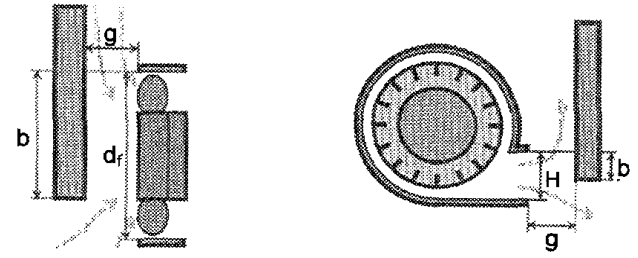

Axial-flow fan obstructed A centrifugal fan obstructed by a square plate (front side) by a square plate (rear side)

(c) Asymmetrical settings

Fig. 4 Geometrical positions between a fan and an obstacle 
いて実験を行った、ファン近傍に設置した障害物の形 状を図 3 に示衣。内柱, 正方形板, 多孔板のいずれか をファンの前方または後方に設置し，ファンと障害物 の腺間を変化させた時の $\mathrm{PQ}$ 特性の変化を調べた。円 柱, 多孔板の直径, および正方形板の辺長 $d_{0}$ は, 供

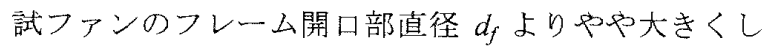
た $\left(d_{o} / d_{f}=1.05 \sim 1.3\right)$ ．なお，ファンの前方に障害物 を設置した実験は図 1 (a) の押込みセットアップを用 いて行い, 後方に設置した実験は図 1 (b) の吸出しセ ットアップを用いて行った。

図 4 に，ファンと障害物の位置関係を示す。基本 的に泣，障害物の中心とファンの通風部の中心とを一 直線状にした状態で隙間 $g$ 変化させた（図 4 (a), (b), 円柱障害物の場合の双表示)：この場合，隙間が $\mathrm{g}=$ 0 になると流路が完全に塞がった状態になる.また， 図 4(c) のように，正方形板を非対称に設置した赛験 も行った。

\section{3. $P Q$ 特性 $の$ 変化}

3.1 軸流ファン 図 5 に, 軸流ファン（表 1 の axial-2）の近傍に円柱障害物を設置した場合の $\mathrm{PQ}$ 特 性の変化を示す。眓 5 (a) がファン前方に設置した場 合，図 5 (b) が後方に設置した場合である、縦軸の $\Delta P_{c h}$ は，チャンバー法で測定したファン前後の圧力 差である。一般に，軸流ファンの $\mathrm{PQ}$ 特性には，高風 量側と低風量側に2つの凸部が存在するが，低風量側 は回転翼が旋回失速を起こしている不安定な状態(7)で あるとされており，通常は高風量側（開放風量の $2 / 3$ 程度以上)で使用される。この範囲では，障害物との 隙間が（ファンのフレーム辺長に対して） $g / d_{L} \geq 0.4$ であれば風量の低下は見られないが， $g / d_{L}<0.2$ にな ると風量の低下が大きくなる。また，障害物をつアン の前方に設置した場合（図５(a)）位方に設置し た場合（図 $5(\mathrm{~b})$ ）よりも性能の低下（風量および圧 力差の低下）が顕著になる。この原因としては，障害 物を前方に設置すると，ファンの回転翼へ流入する流 れの向きが変化して，翼まわりの流動が悪化すること が考えられる．なお，障害物をファンの後力に設置す ると，障害物の無い時よりも低風量側で压力が高くな る傾向がある。この原因は明らかではないが，後方に 障害物が設置されると流路の急拡大が緩和されて圧力 損失が緩和されることが考えられる，なお，他の軸流 ファン（表 1 の axial-1，3）においても，図 5 (a), (b) で見られる上記の傾向が確認できた。

図 6 に法，軸流ファン（axial-3）の前方に多孔板を

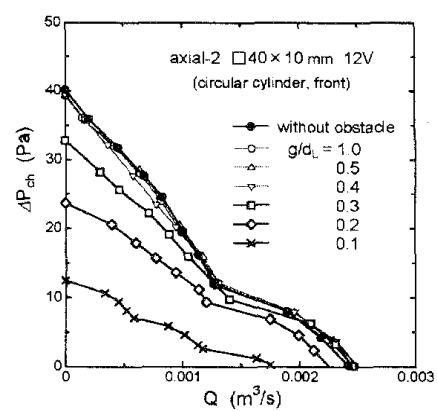

(a) Front side

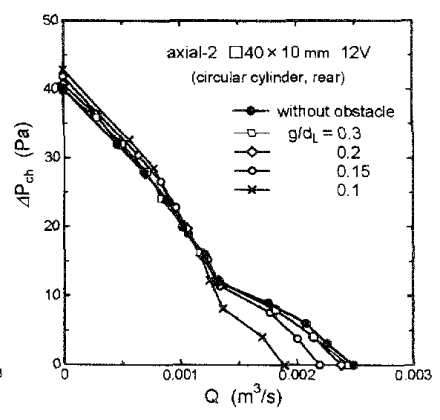

(b) Rear side
Fig. 5 PQ characteristic of axial-2 obstructed by a circular cylinder $\left(d_{o} / d_{f}=1.05\right)$

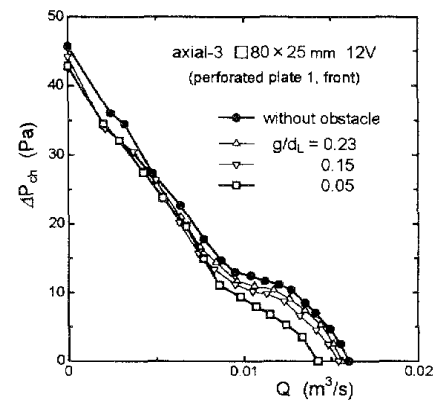

(a) perforated 1 (front side)

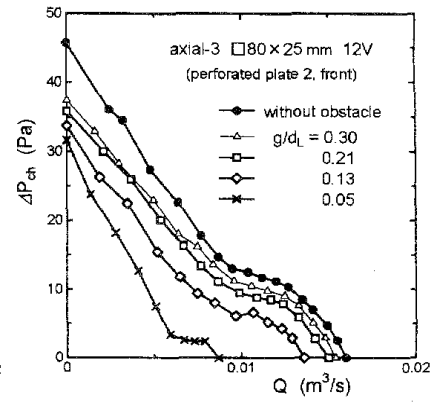

(b) perforated 2 (front side)
Fig. 6 PQ characteristic of axial-3 obstructed by a perforated plate $\left(d_{o} / d_{f}=1.08\right)$

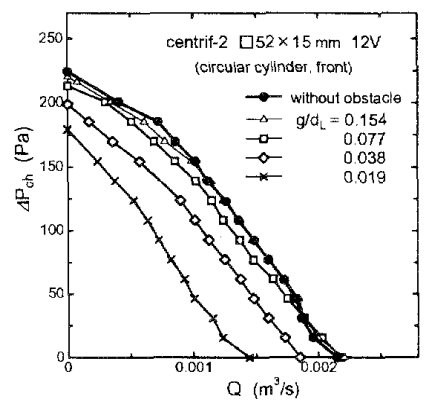

(a) Front side

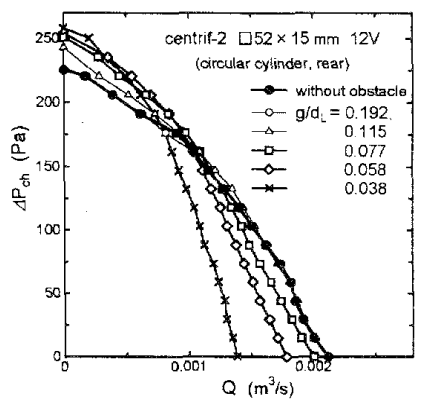

(b) Rear side
Fig. 7 PQ characteristic of centrif- 2 obstructed by a circular cylinder $\left(d_{o} / d_{f}=1.11\right)$

設置した場合を示す。多孔板 1 （図6(a)）は開口率 が 0.5 程度と比較的大きいため, 流動抵抗が小さく, ファンに近接させても性能の低下は僅かであるが，多 孔板 2 は開口率が 0.3 程度と小さいため, 冈柱障害物 の場合（図 5 (a)）と同様に，近接させるに従い風量， 压力差が共に低下している。

3.2 遠心ファン 図7に, 遠心ファン (centrif2）の場合の $\mathrm{PQ}$ 特性の変化を示す。一般に, 遠心フ アンでは，軸流ファンで見られるような高風量側と低 風量側における特性の違いはなく，1つの凸形の曲線 となる。障害物を前方に設置した場合（図 7 (a)）は， 
障害物の近接と共に風量および压力差が共に低下する が，後方に設置すると（図７(b)），風量は低下する ものの，低風量側では压力差が逆に上昇する傾向があ る．つまり，軸流ファンの場合と定性的には同様な傾 向を示す．ただし，軸流ファンでは隙間が $g / d_{L}=0.2$ を下回ると風量の低下が顕著になるのに対し，遠心フ アンでは風量の低下が顕著になるのは $g / d_{L}=0.08$ 程 度以下の場合であり，遠心ファンの方が障害物の近接 の影響を受けにくいと言える.

\section{3 障害物を非対称に設置した場合ここれまで} は，障害物をファンの開口部に対して対称に設置した 場合の結果を示したが，障害物を非対称に設置すると 翼に㗢く力が周方向に不均一になり，これが性能の低 下をもたらす恐れがある。そこで，図 4 (c) のように 正方形板を非対称に設置した実験を行い，対称に設置 した場合との違いを調べた。

図 8 に, PQ 特性の変化（軸流ファンの場合）を示 す，正方形板をファンの前方に設置した場合（図 8 (a)）は, 隙間 $g=2 \mathrm{~mm}\left(g / d_{L}=0.05\right)$ の状態でファン 開口部の閉塞長さ $b / d_{f}$ (図 4 (c) 参照) を変化させ, 後方に設置した場合（図 $8(\mathrm{~b})$ ) 法, 隙間 $g=0$ の状態 で b/d d を変化させた，いずれの場合も，b/d が増加し て開口面積が小さくなるにつれて風量の低下が顕著に なる。また，前方設置の場合は，開口面積が小さくな るにつれて風量と圧力差が共に低下しているのに対し， 後方設置の場合は楴切圧力は低下せず，風量のみが低 下している，つまり，障害物を対称に設置した場合 （図 5 ）と類似の傾向を示している，なお，遠心ファ ンの場合も，軸流ファン（図 8 ） と定性的には同様の 傾向が見られた。

\section{4. 開放風量の低下}

4. 1 断面積の定義 ファンと障害物の隙間が最小 となる面積 $A_{g}$ がファン内部の最小通風面積 $A_{f}$ より小 さくなると, 流動抵抗が大きくなり, 風量の低下が顕 著になると考えられる.そこで, 隙間開口比 $\beta_{g}=$ $A_{g} / A_{f}$ を定義し, 風量低下との関係を調べた.

ファンの最小通風面積 $A_{f}$ とは，ファン内部におい て流線と直交する断面が最小となる面積であり，ここ では，ファン吐出口の面積（図 9 の斜線の面積）を $A_{f}$ と定義した，すなわち，軸流ファンの場合は $A_{f}=$ $\pi\left(d_{f}^{2}-d_{h}{ }^{2}\right) / 4-A_{s}$ ( $A_{s}$ : 半径方向の支柱断面積)，遠心 ファンの場合は $A_{f}=H W$ とした。

また，隙間面積 $A_{g}$ は，ファンと障害物の隙間にお いて，流線と直交する断面が最小となる面積で定義さ

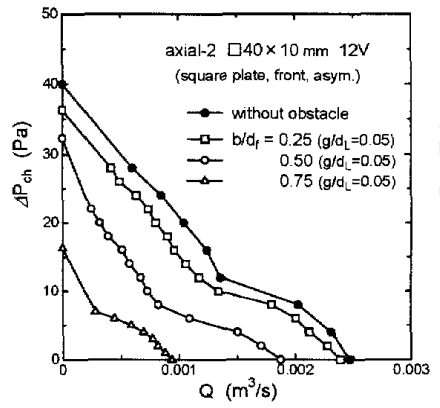

(a) Front side $\left(g / d_{L}=0.05\right)$

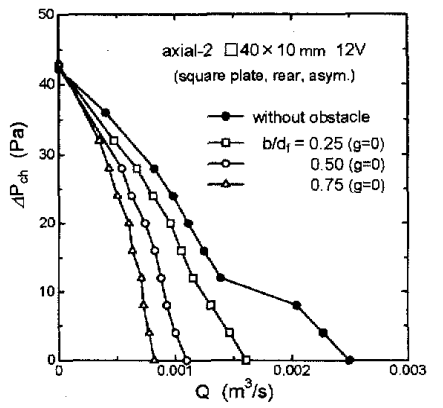

(b) Rear side $(g=0)$
Fig. 8 PQ characteristic of axial-2 obstructed by a square plate set asymmetrically $\left(d_{o} / d_{f}=1.3\right)$

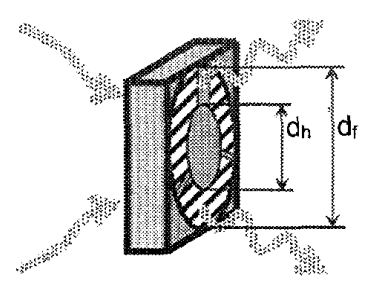

(a) Axial-flow-fan

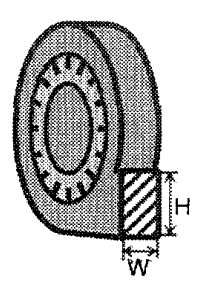

(b) Centrifugal fan
Fig. 9 Definition of the minimum fan-flow area $A_{f}$

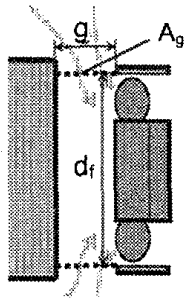

(a) Axial-flow-fan (front)

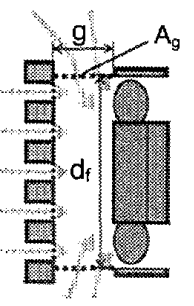

(c) Perforated plate

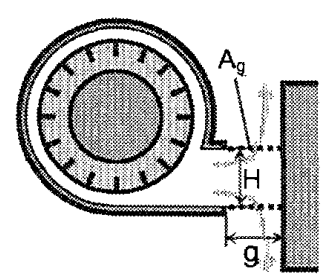

(b) Centrifugal fan (rear)

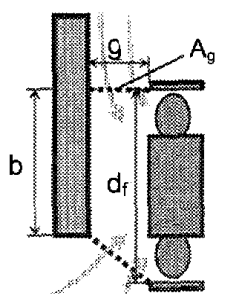

(d) Square plate (asymmetrical)
Fig. 10 Definition of the minimum gap-flow are $A_{g}$

れる。例えば，円柱障害物や正方形板（対称設置, 図 10 (a), (b)）の場合は, 隙間面積 $A_{\boldsymbol{g}}$ はファンの開口部 周長と隙間 $g$ との積で表すことができる。つまり， 軸流ファンの場合と遠心ファンの前方設置の場合（図

（a)）は $A_{g}=\pi d_{f} g$ となり，遠心ファンの後方設置の 場合（図 $10(\mathrm{~b})$ ) は $A_{g}=2(H+W) g$ となる（簄密には， 上記断面が流線と直交するとは限らないが，単純化の ため，ここでは上記断面積を隙閒面積とした）。また， 
多孔板の場合（図 10 (c)）注，ファン開口部周長と隙 間との積 $\pi d_{f} g$ に穴の面積の総和を加えた面積とした なお，非対称設置の場合（図 10 (d)）は隙間面積を特 定するのが難しいが，図の点線で示寸領域を基に隙間 面積を見積もった。

4.2 開放風量の低下 図 11 に, 隙間開口比 $\beta_{g}=$ $A_{g} / A_{f}$ 之開放風量 $\left(\Delta P_{c h}=0\right.$ 風量）の低下率 $Q / Q_{0} \sigma$ 関係寺示す． $Q_{0}$ は障害物が無い時の開放風量である. なお，図5〜8からわかるように，高風量側では $\mathrm{PQ}$ 特性が相似形を保って変化する傾问があり，通常使用 される高風量の範国であれば，ファンの風量低下は開 放風量の場合で代表されると考えられる.

図11(a)に，軸流ファン（axial-1〜3）の近傍に障害 物（円柱，正方形板，多孔板）を設置した場合を，ま た図 11(b)には，遠心ファン (centrig-1，2）の近傍に 障害物（円柱，正方形板）を設置した場合を示す， フ アンの前方に障害物を設置した場合を黒塗りの記号で, 後方に設置した場合を白抜きの記号で表したが，それ ぞれの場合における風量の低下 $Q / Q_{0}$ は，ファンの大 きさ，翼の回転数（供給電圧），障害物の形状にあま り依存しておらず，隙間開口比 $\beta_{g}$ の值によって注漹 一意に洟まっている。なお，障害物を前方に設置する と，後方に設置するより風量の低下が顕著になるが， これは前述のように，ファン吸込口で流れの向きが変 化し，これが回転翼まわりの流れを悪化させるためと 考えられる。なお，前述のように，障害物との隙間 $g / d_{L}$ で比較すると，遠心ファンの方が障害物の影響を 受けにくい（図 5, 図 7) が，隙間面積比 $\beta_{g}$ で整理 すると，軸流ファンも遠心ファンもほぼ同様の風量低 下を示すことがわかる。

図 11(c)には，軸流ファン（axial-2）および遠心フ アン（centrif-2）の近傍に正方形板を非詨称に設置し た場合を示す，対称に設㯰した時（図 11(a)，(b)）と 比べると， $\beta_{g}=1$ 前後での風量低下(前方設置の場 合）が小さいが，これは，回転翼まわりの流れの悪化 が部分的にしか起こらないためと推測できる。ただし， 隙間開口比 $\beta_{g}$ と風量低下率 $Q / Q_{0}$ の関係, すなわち, $\beta_{g}<2$ で風量が低下し始め， $\beta_{g}<1$ で風量の低下が顕 著になるという全体的な傾向は，障害物を対称に設置 した場合と基本的には同じである。

4.3 風量の低下に関する考察こここで，開放風 量が低下する原因について考察する。まず，図 12 (a) のように，ファンの前後に十分広い空間がある場合を 考える。この時, ファンの吸込口と吐出口におけるエ ネルギーバランスは，流れが定常で非粘性・非圧縮を 仮定すると，次式で表すことができる。

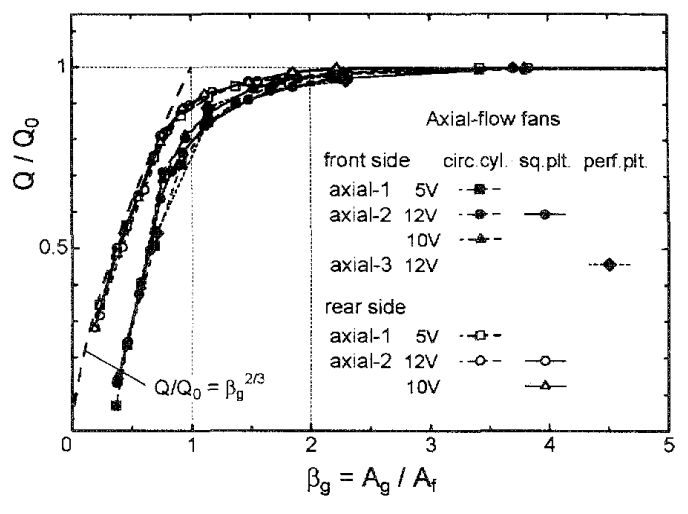

(a) Axial-flow fans (symmetrical settings)

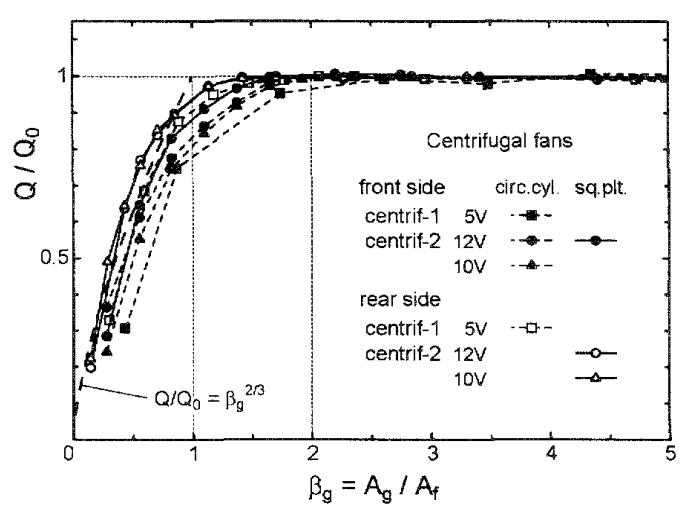

(b) Centrifugal fans (symmetrical settings)

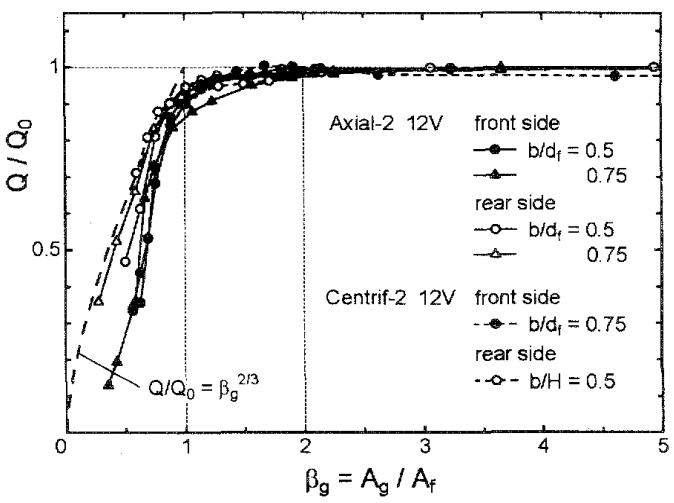

(c) Asymmetrical settings

Fig. 11 Reduction of the maximum flow rate $Q / Q_{0}$ against the gap opening ratio $\beta_{g}$

$$
0.5 \rho Q_{0} u_{f}^{2}+P_{i} A_{f} u_{f}+W=0.5 \rho Q_{0} u_{f}^{2}+P_{e} A_{f} u_{f}
$$

左辺が，吸込口における流体の運動エネルギ一と圧力 による仕事との和に，ファンが流体になす仕事(ファ ン内部の压力損失を除いた正味の仕事率）W $W$ を加え たものであり，右辺が，吐出口における運動エネルギ 一と圧力による仕事との和である，なお，実際には風 速や圧力は断面内で分布を持つが，ここでは単純化の ため一定值として扱っている，また， $A_{f} お よ ひ ゙ ~ u_{f}$ は ファン内部で一定としている。 


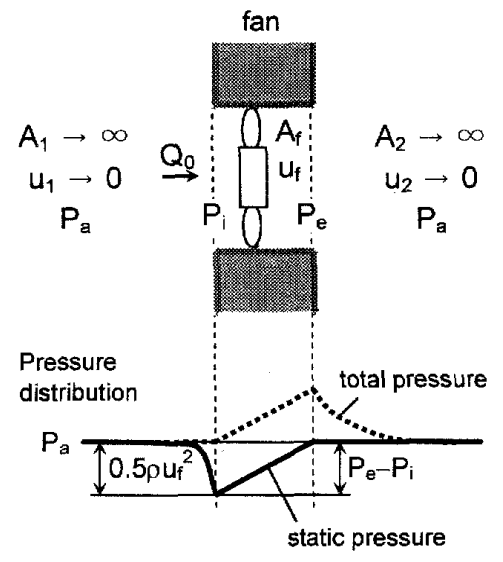

(a) Without obstacle

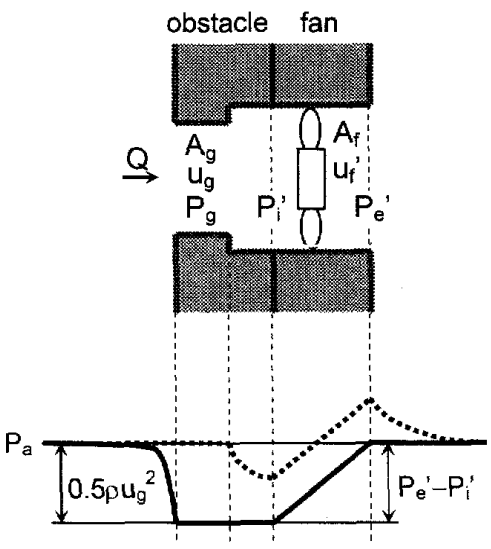

(b) Obstructed at front side

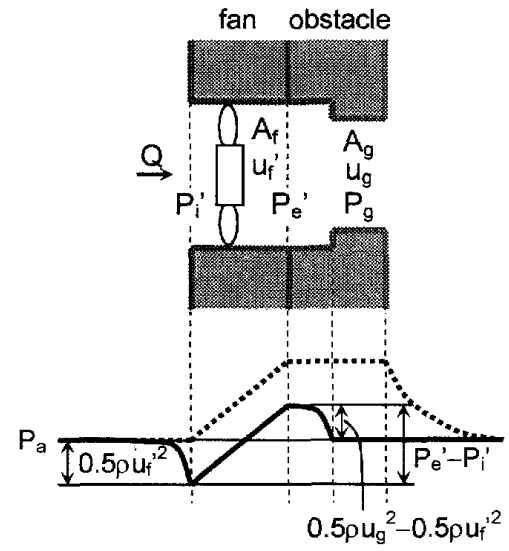

(c) Obstructed at rear side

Fig. 12 Schematic diagram of obstructed flows

図 12 (a)の下に, 流れ方向の圧力分布を模式的に表 した（単純化のため, 壁面摩擦損失や流れの縮小部に おりる压力損失は十分小さいとし，流れの拡大部では 動圧がすべて散逸すると仮定した分布を表した）。こ の分布から, ファン吸込ロと吐出曰の静圧差は $P_{e}-P_{i}=0.5 \rho u_{f}^{2}$ と表すことができ，また，風量は $Q_{0}=u_{f} A_{f}$ であるので，これらを式(1)に代入すると 次式を得る.

$$
W=0.5 \rho Q_{0}^{3} / A_{f}^{2}
$$

次に，図 12 (b) のように，ファンの前方に障害物が 設置され，隙間面積 $A_{g}$ がファンの通風面積 $A_{f}$ より狭 くなった場合 $\left(A_{g}<A_{f}\right)$ を考える.この時, ファンの 仕事率が $W^{\prime}$ であるとすると, ファンの吸込口と吐出 ロにおけるエネルギーバランスは次式で表される。

$$
0.5 \rho Q\left(u_{f}^{\prime}\right)^{2}+P_{i}^{\prime} A_{f} u_{f}^{\prime}+W^{\prime}=0.5 \rho Q\left(u_{f}^{\prime}\right)^{2}+P_{e}^{\prime} A_{f} u_{f}^{\prime}
$$

压力分布の模式図から，ファン吸这口と吐出部の静圧 差は $P_{e}^{\prime}-P_{i}^{\prime}=0.5 \rho u_{g}^{2}$ と表すことができ，また，風量 は $Q=u_{g} A_{g}$ であるので, これらを式(3) に代入すると 次式を得る。

$$
W^{\prime}=0.5 \rho Q^{3} / A_{g}{ }^{2}
$$

もし障害物を設置してもファンの仕事率が変化しない $\left(W^{\prime}=W\right)$ とすれば，式(2),(4)より次式が成り立つ.

$$
Q / Q_{0}=\left(A_{g} / A_{f}\right)^{2 / 3}=\beta_{g}^{2 / 3} \quad\left(\beta_{g}<1\right)
$$

つまり, ファンの性能が変化しなくても $\left(W^{\prime}=W\right)$, 障 害物を設置して隙間開口比 $\beta_{g}$ が 1 より小さくなると 風量の低下が起こる.これは, 図 12 の圧力分布から わかるように，障害物を設置するとファン吸込口と吐 出口の圧力差 $P_{e}^{\prime}-P_{i}^{\prime}$ が大きくなるためであり, その
結果，ファンの仕事の多くが圧力差に対抗するために 費やされることになる。この時, チャンバー法で測定 した圧力差（ファンの十分遠方の静圧差）は $\Delta P_{c h}=0$ のままであるため, 開放風量 $\left(\Delta P_{c h}=00\right.$ 風量) は障 害物を近接させることによって低下することになる。

次に, 図 12 (c) のように, ファンの後方に障害物が 設置されて隙閐面積が $A_{g}<A_{f}$ になった場合を考える. この場合も，ファン吸込口と吐出口におけるエネルギ 一バランスは式(3)と同一の式で表される，また，圧 力分布の模式図から，ファン吸込口と吐出部の静圧差 は $P_{e}^{\prime}-P_{i}^{\prime}=0.5 \rho u_{g}^{2}$ と表すことができるので，障害物 をファンの前方に設置した場合と同一の関係式（式 (5)）が導かれる.

この関係式 $\left(Q / Q_{0}=\beta_{g}^{2 / 3}, \beta_{g}<1\right)$ を図 11 に破線で 示した，実際には，粘性による壁面摩擦損失や流れ力 向の変化に伴う圧力損失が起こり，また，障害物を前 方に設置した場合にはファンの流入角変化による回転 翼まわりの流れの悪化（ファン自体の性能低下）が起 こると考えられるため，特に障害物を前方に設置した 場合には破線より風量が低下するが，障害物を後方に 設置した場合には良い近似を与えている。なお，遠心 ファンでは（図 11(b)） $\beta_{g}<1$ において風量が破線を 上回っているが，遠心ファンの PQ 曲線（図 7）は軸 流ファンとは異なり大きな凸型をしているため，障害 物による圧力損失がある程度大きくなった力がファン の仕事率 $W^{\prime}$ （ファン前後の全圧差 $\times$ 風量）が大きく なるためと考えられる。

本実験で得られた風量低下の関係（図 11）は，従 来の実験結果とも良く一致している，例えば，軸流つ アンの後方に平板状の障害物を近接させた袁らの害 験 ${ }^{(3)} や ，$ 本実験よりやや大きめの軸流ファン（フレ 一ム辺長 $80 \sim 120 \mathrm{~mm}$ ）の前方または後方に平板障害 
物を近接させた実験 ${ }^{(8)}$ でも，本実験と同様に隙間面積 比 $\beta_{g}$ を用いて結果を整理すると，風量の低下 $Q / Q_{0}$ は 図 11 と良く一致する。すなわち，図 11 に示した隙閒 面積比 $\beta_{g}$ と風量低下 $Q / Q_{0}$ の関倸は, ファンの種類 （軸流/遠心）や大きさ，翼の回転数（供給電圧）， 障害物の形状や設置位置（対称/非対称）といった条 件に注あまり依存しない，普遍性の高い結果であると 言える。ささらに，筐体入口の開口面積を狭くした福江 らの実験結果 ${ }^{(4)}$ も，開口面積比 $\beta=A_{i} / A_{f}\left(A_{i}\right.$ : 筐体の 入口開口面積）と風量低下 $Q / Q_{0}$ の関係汢図 11 と良 く一致する。すなおち，障害物を近接させた場合だけ でな，一般に流路の開口面積が狭くなったときには， ファンの風量は図 11 の傾向に従って低下寸るもの上 考えられる。

\section{5. 結論}

小型の軸流ファン及び遠心ファンの近傍に障害物 設置した時の $\mathrm{PQ}$ 特性の変化および開放風量の低下に ついて調べた。 その結果, 以下のことが明らかになっ た.

（1）ファンと障害物の隙間最小面積を $A_{g}$ ，ファ ン内部の最小通風面積を $A_{f}$ とすると, 風量は隙間開 口比 $\beta_{g}=A_{g} / A_{f}$ に支配されて低下方ることが実験的に 明らかになった。すなわち， $\beta_{g}>2$ では風量注ほとん ど低下しないが， $\beta_{g}<2$ で風量の低下が始まり， $\beta_{g}=$ 1 では 10２0\% 程度低下する．また， $\beta_{g}<1$ になる と風量の低下が顕著になる(障害物をファンの後方に 設置した場合は，風量はほぼ $\beta_{g}$ の $2 / 3$ 乗に比例して 低下する）。この関倸は，ファンの種類（軸流/遠 心や大きさ，翼の回転数（供給電圧），障害物の形 状や設置位置（対称/非対称）といった条件にはほと んど依存しない，普遍性の高い結果である。
（2）ファンの前方に障害物を設置寸ると，後方 に設置した場合と比べて $\beta_{g}<2$ における風量低下が顕 著になる。

なお，本研究は日本機械学会 $\mathrm{RC} 227$ および $\mathrm{RC} 239$ 研究分科会（熱WG）の一環として行ったものであり， 分科会での討論等を通じ貴重な助言をいただいた。ま た，実験データの取得には当時防衛大学校学生の伊藤 史晃氏，濱田倫行氏，長谷川勇太氏，横山大地氏，中 島快氏のご協力をいただいた。ここに謝意を表扵。

\section{文献}

(1) Ikegawa, M., Takahashi, T. and Yamada, M., Performance Evaluation of Cooling Fans for a Compact PC (in Japanese), Proc. Thermal Engineering Conference 03, Kanazawa, Japan (2003), pp.113-114.

(2) Nakayama, T., On the fan performance (in Japanese), Lecture material of the RC214 Research Project, (2004), The Japan Socirty of Mechanical Engineers.

(3) Yuan, H., Funazaki, K., Yamada, K. and Shimada, T., Studies on Aero-Thermal Performance of a Cooling Fan Used in a Narrow Space (Experimantal and Numerical Analyses on Time-Averaged Characteristics) (in Japanese), Turbomachinery, Vol.36-6 (2008), pp.369-377.

(4) Fukue, T., Yoshimoto, T., Ishizuka, M. and Nakagawa, S., The Effects of Frame and Inlet Sizes of Electronic Casingmounted Cooling Fans on Their P-Q Characteristics (in Japanese), Thermal Scinece \& Engineering, Vol.16 (2008), pp.147-156.

(5) Nakamura, H. and Igarashi, T., Fabrication of an Experimental Setup for the Fan Performance Measurements (in Japanese), Research Report of the RC214 Research Project, (2006), pp. 805-812, The Japan Socirty of Mechanical Engineers.

(6) JIS Z 8762, Measurement of Fluid Flow by Means of Orifice Plates, Nozzles and Venturi Tubes Inserted in Circular Cross-Section Conduits Running Full (in Japanese), (1995), Japan Standards Association.

(7) JSME Mechanical Engineers' Handbook, $\gamma 2$ Fluid Machinery, (2007), p.174, The Japan Society of Mechanical Engineers.

(8) Ishizuka, M., Thermal Design of Electronic Equipment, (2003), pp.114-118, Maruzen. 